\title{
BMJ Association between childhood OPen adversities and adulthood depressive symptoms in South Korea: results from a nationally representative longitudinal study
}

To cite: Kim S-S, Jang $\mathrm{H}$, Chang HY, et al. Association between childhood adversities and adulthood depressive symptoms in South Korea: results from a nationally representative longitudinal study. BMJ Open 2013;3:e002680

doi:10.1136/bmjopen-2013002680

- Prepublication history for this paper is available online. To view these files please visit the journal online (http://dx.doi.org/10.1136/ bmjopen-2013-002680)

Received 2 February 2013 Accepted 17 June 2013

For numbered affiliations see end of article.

Correspondence to Dr Seung-Sup Kim; ssk3@korea.ac.kr

\section{ABSTRACT}

Objective: To examine how childhood adversity (ie, parental death, parental divorce, suspension of school education due to financial strain or being raised in a relative's house due to financial strain) is associated with prevalence and incidence of adulthood depressive symptoms and whether this association differs by gender and by age in South Korea.

Design: Prospective cohort design.

Setting: Nationally representative longitudinal survey in South Korea.

Participants: 11526 participants in South Korea.

Outcome measure: Prevalence and incidence of adulthood depressive symptoms were assessed as a dichotomous variable using the Centers for Epidemiologic Studies Depression (CES-D) Scale in 2006 and 2007.

Results: In the prevalence analysis, each of the four childhood adversities was significantly associated with a higher prevalence of adulthood depressive symptoms. The higher incidence of depressive symptoms was associated with suspension of school education (OR $1.55,95 \% \mathrm{Cl} 1.32$ to 1.82 ) and parental divorce (OR $1.65,95 \% \mathrm{Cl} 1.00$ to 2.71). In the agestratified analyses, prevalence of depressive symptoms was associated with all CAs across different adulthoods, except for parental divorce and late adulthood depressive symptoms. After being stratified by gender, the association was significant for parental divorce (OR 3.76, 95\% $\mathrm{Cl} 2.34$ to 6.03) in the prevalence analysis and for being raised in a relative's house (OR $1.89,95 \% \mathrm{Cl} 1.21$ to 2.94 ) in the incidence analysis only among women.

Conclusions: This study suggests that childhood adversity may increase prevalence and incidence of adulthood depressive symptoms, and the impact of parental divorce or being raised in a relative's house due to financial strain on adulthood depressive symptoms may differ by gender.

\section{ARTICLE SUMMARY}

Article focus

- A growing body of studies showed that adulthood depression is linked to early harmful exposures called childhood adversities (CAs), such as long-term financial strain, sexual abuse, separation from parents and parental death

- The first goal of this study was to examine how CA (ie, parental death, parental divorce, suspension of school education due to financial strain or being raised in a relative's house due to financial strain) was associated with prevalence and incidence of adulthood depressive symptoms in South Korea.

- The second goal of this study was to investigate whether the association between CAs and adulthood depressive symptoms differs by gender and by age (early: 18-39, middle: 40-59 and late adulthood: 60-98 years old) in South Korea.

Key messages

- CAs were associated with higher prevalence and incidence of adulthood depressive symptoms after adjusting for covariates including adulthood as well as childhood socioeconomic status in South Korea.

- The impact of childhood experience of parental divorce or being raised in a relative's house due to financial strain on adulthood depressive symptoms may differ by gender in South Korea.

Strengths and limitations of this study

- The observed association between CAs and adulthood depressive symptoms would be robust against potential recall bias because of the longitudinal study design.

- Although we assessed four different CAs, other CAs such as physical abuse or emotional abuse that are known to be associated with adulthood depressive symptoms were not measured in this study. 


\section{INTRODUCTION}

Depression is one of the leading causes of disease burden and disability. ${ }^{1}$ The contribution of depression to the burden of disease is on the rise and is expected to be the primary influence by $2030 .^{2}$ Recent studies with the life course perspective have added new insights to the aetiology of depression. A growing body of studies shows that adulthood depression is linked to early harmful exposures called childhood adversities (CAs), such as long-term financial strain, sexual abuse, separation from parents and parental death. ${ }^{3-6}$

However, prior studies contained several limitations. First, findings of association between CA and adulthood depression are inconsistent. For example, some studies reported positive associations between parental death during childhood and adulthood depression ${ }^{7}{ }^{8}$; others found no association. ${ }^{9-12}$ Second, although a previous study suggested that women could be more sensitive to the effects of CAs, ${ }^{13}$ little is known about gender differences in the association between CAs and adulthood depression. Third, the role of adulthood socioeconomic status (SES) is not clear in the association between CA and adulthood depression although adulthood SES is often assumed to be an important pathway linking CA to adulthood depression. Harper et al reported no significant association between childhood SES and adulthood depression when they adjusted for adulthood SES, ${ }^{13}$ but other studies reported that association between CA or childhood SES and adulthood depression remained significant after adjusting for adulthood SES. ${ }^{4614}$ Fourth, whether the effect of CAs extends to late adulthood is not clear. Ross and Mirowsky ${ }^{14}$ reported no direct intrapsychic effects of parental divorce on adult depression, while Kessler $e t a l^{11}$ reported a weaker but significant association between CAs and later onset psychiatric disorders.

Finally, most studies were conducted in the USA $^{511} 1516$ or in European countries ${ }^{4617}{ }^{18}$; relatively few studies have been conducted to examine the association between CAs and adulthood depression in an Asian country. ${ }^{19} 20$

To fill these knowledge gaps, this study explored the association between $\mathrm{CA}$ and adulthood depression using nationally representative data in South Korea. Specifically, this study sought to answer the following five research questions.

1. What is an association between CA (ie, parental death, parental divorce, suspension of school education due to financial strain or being raised in a relative's house due to financial strain) and prevalence and incidence of adulthood depressive symptoms in South Korea?

2. How does the association between $\mathrm{CA}$ and prevalence and incidence of adulthood depressive symptoms change when adulthood SES is adjusted?

3. Is there a dose-response relationship between the number of CAs and adulthood depressive symptoms?
4. How does the association between CA and prevalence and incidence of adulthood depressive symptoms differ by gender?

5. How does the association between CAs and prevalence and incidence of adulthood depressive symptoms differ by age groups?

\section{METHODS}

\section{Study population}

This study analysed data from the Korean Welfare Panel Study (KOWEPS), launched in 2006. This is a panel survey conducted annually by the Korean Institute of Social and Health Affairs with the Social Welfare Research Institute of Seoul National University. KOWEPS recruited 7072 households (18 856 respondents) from nationally representative 'Korean People's Life Status Survey', used two-stage stratified cluster sampling by region and income based on 'Korea Census (2005)' database. KOWEPS survey data were collected through person-to-person interview by visiting each household. These results are publicly available from the website (http://www.koweps.re.kr). We analysed data from the first (2006) and second (2007) waves of KOWEPS because the measurement of CA was only included in the first wave survey. The follow-up rate of second wave of KOWEPS was 91.3\%. Among 18856 respondents in the first wave, we excluded respondents who were less than 18 years old, did not participate in the second wave of KOWEPS or had missing values for depressive symptoms, CA or any covariates. As a result, 11526 respondents were included to examine the association between CA and prevalence of adulthood depressive symptoms. After excluding 2963 respondents who had depressive symptoms at the first wave of KOWEPS (2006), 8563 respondents were included in the incidence analysis of adulthood depressive symptoms. This research received Institutional Review Board (IRB) exemption from the Office of Human Research Administration at the Harvard School of Public Health.

\section{Measures}

\section{Depressive symptoms}

A version of the 11-question Centers for Epidemiologic Studies Depression Scale (CES-D) was used to screen depressive symptoms at baseline (the first wave of KOWEPS in 2006) and at follow-up survey (the second wave of KOWEPS in 2007). CES-D has been validated in South Korea. ${ }^{21}$ For each of 11 questions, respondents could answer from 0 to 3 . The summed total score of 11 questions ranged from 0 to 33. A cut-off of nine points or more was used to define depressive symptoms. ${ }^{22}$ To obtain more reliable estimates of the prevalence of adulthood depressive symptoms, we calculated an average of CES-D scores from the first and second waves of KOWEPS, and the resulting score was used to screen adulthood depressive symptoms. Incidence of 
adulthood depressive symptoms was defined when respondent has depressive symptoms at follow-up survey among the respondents without depressive symptoms at baseline survey.

\section{Childhood adversities}

Four different CAs were assessed in the first wave of KOWEPS using the following questions: "During your childhood (0-17 years old), did you ever experience (1) divorce of parents, (2) death of parent, (3) being raised in a relative's house due to financial strain in your family or (4) suspension of school education due to financial strain in your family?" Respondents could answer Yes (coded as 1) or No (coded as 0 ) for each of the four questions. In addition, we created the variable 'the number of CAs' by calculating the total number of CAs experienced by each respondent.

\section{Covariates}

As potential confounders, we considered six variables that may be associated with both CA as well as adulthood depressive symptoms based on prior literature: survey of respondent's age and sex, and four variables to assess childhood SES (ie, education of each parent ${ }^{23}$ and occupation of each parent ${ }^{23}{ }^{24}$ ). Education of each parent was classified into five categories using 'college graduate or more' as a reference: no formal education, elementary school graduate, middle school graduate, high school graduate and college graduate or more. Occupation of each parent was measured following a classification of International Standard Classification of Occupations ${ }^{25}$ and was classified into three categories following a previous paper analysed KOWEPS ${ }^{26}$ : nonmanual labour (ie, managers (including government officials), professionals, technicians and associate professionals, and clerical support workers), manual labour (ie, service and sale workers, skilled agricultural, forestry and fishery workers, craft and related trades workers, plant and machine operators and assemblers, and elementary occupations), homemaker and others (ie, armed forces occupations). Each of six potential confounders was included as a categorical variable in the analyses.

In addition to these potential confounders, we evaluated how the associations changed when we additionally adjusted for adulthood SES of survey respondents because adulthood SES could be a mediator in the pathway linking CAs and adulthood depressive symptoms. Adulthood SES was assessed using three different measures of respondents: employment status, income and education level. Education was coded into four categories: junior high or less, high school graduate, college graduate and university graduate or more. An equivalised household income was calculated by dividing the sum of household income by the square root of the number of household members. A variable for income was then generated with four levels using the quartiles of the calculated equivalised income. Employment status was classified into seven categories: full-time permanent worker, precarious worker, employer, self-employed worker, fulltime student, unpaid family worker and unemployed including housewives. A detailed explanation of this categorisation was provided in previous studies that analysed KOWEPS. ${ }^{27}{ }^{28}$ Each of the three measures for adulthood SES was included as a categorical variable in the analysis. All covariates included in the analysis were assessed in the first wave of KOWEPS.

\section{Data analysis}

Logistic regression was applied to investigate the association between $\mathrm{CA}$ and prevalence and incidence of adulthood depressive symptoms and to examine how the associations change when we additionally adjust for respondent's adulthood SES. Incidence analysis was conducted after excluding the people with depressive symptoms at first wave of KOWEPS. To evaluate whether the association differs by age, we examined the association between CA and prevalence and incidence of depressive symptoms after being stratified by early (18-39 years old), middle (40-59 years old) and late adulthood (60-98 years old). Finally, to examine whether the association differs by gender, we created interaction terms by multiplying gender and each of the four CAs in a fully adjusted model and checked $p$ values of those interaction terms in both the prevalence and the incidence analysis. If the interaction term is statistically significant $(p<0.05)$ we examined the association between CA and adulthood depressive symptoms after stratification by gender. Because depressive symptoms of respondents in the same family (5246 among 11526 respondents in the prevalence analysis and 4875 among 8563 respondents in the incidence analysis had family members in the study population) were likely to be correlated to each other, the Huber-White sandwich estimator was used to calculate OR and $95 \%$ CI robust to within-family clustering. ${ }^{29}$

\section{RESULTS}

Table 1 presents the distribution of study population and the prevalence and incidence of depressive symptoms by age, sex and childhood SES (ie, education and occupation of each parent). The overall prevalence of depressive symptoms was significantly higher among women and the elderly. Depressive symptoms appeared to be more common among respondents whose parents had no formal education or whose parents were manual workers (table 2).

Table 3 displays the distribution of CAs and the association between $\mathrm{CA}$ and the prevalence of adulthood depressive symptoms. The highest prevalence of CA was for the parental death (18\%) and the lowest prevalence was for the parental divorce $(1.3 \%)$. We found strong associations between each of the four CAs and adulthood depressive symptoms (table 3). After adjusting for potential confounders, adulthood depressive symptoms were associated with childhood experience of parental death 
Table 1 Distribution of key covariates and prevalence and incidence of adulthood depressive symptoms in South Korea

\begin{tabular}{|c|c|c|c|c|c|c|}
\hline \multirow[b]{3}{*}{ Key covariates } & \multicolumn{3}{|c|}{$\begin{array}{l}\text { Study population for prevalence } \\
\text { analysis }\end{array}$} & \multicolumn{3}{|c|}{$\begin{array}{l}\text { Study population for incidence } \\
\text { analysis }\end{array}$} \\
\hline & \multirow{2}{*}{$\begin{array}{l}\text { Total } \\
\mathbf{N}\end{array}$} & \multicolumn{2}{|c|}{$\begin{array}{l}\text { Prevalence of depressive } \\
\text { symptoms }\end{array}$} & \multirow{2}{*}{$\begin{array}{l}\text { Total } \\
\mathbf{N}\end{array}$} & \multicolumn{2}{|c|}{$\begin{array}{l}\text { Incidence of depressive } \\
\text { symptoms }\end{array}$} \\
\hline & & N (\%) & p Value ${ }^{\star}$ & & N (\%) & p Value ${ }^{\star}$ \\
\hline Sex & & & $<0.001$ & & & $<0.001$ \\
\hline Male & 5143 & 879 (17.1) & & 4118 & $585(14.2)$ & \\
\hline Female & 6383 & $1795(28.1)$ & & 4445 & 902 (20.3) & \\
\hline Age (years) & & & $<0.001$ & & & $<0.001$ \\
\hline $18-29$ & 1584 & $185(11.7)$ & & 1350 & $184(13.6)$ & \\
\hline 30-39 & 2393 & 315 (13.2) & & 2004 & $274(13.7)$ & \\
\hline $40-49$ & 2068 & 399 (19.3) & & 1605 & $230(14.3)$ & \\
\hline $50-59$ & 1682 & $413(24.6)$ & & 1258 & $222(17.7)$ & \\
\hline 60 or more & 3799 & $1362(35.9)$ & & 2346 & $577(24.6)$ & \\
\hline Education & & & $<0.001$ & & & $<0.001$ \\
\hline Junior high school or less & 5101 & $1806(35.4)$ & & 2423 & $778(24.3)$ & \\
\hline Junior high school graduate & 3508 & $590(16.8)$ & & 2398 & $414(14.7)$ & \\
\hline College graduate & 1177 & $133(11.3)$ & & 861 & $134(13.5)$ & \\
\hline University graduate or more & 1740 & $15(8.3)$ & & 1394 & $161(10.4)$ & \\
\hline Employment status & & & $<0.001$ & & & $<0.001$ \\
\hline Unemployed & 4744 & $1586(33.2)$ & & 2422 & $520(20.4)$ & \\
\hline Precarious employment & 2010 & $445(22.1)$ & & 1230 & $296(19.4)$ & \\
\hline Unpaid family worker & 742 & $143(19.3)$ & & 475 & $128(21.2)$ & \\
\hline Self-employed & 1635 & $323(20.0)$ & & 1045 & $236(18.4)$ & \\
\hline Permanent employment & 1870 & $133(7.1)$ & & 118 & $165(9.8)$ & \\
\hline Business owner & 142 & $14(9.9)$ & & 104 & $18(14.8)$ & \\
\hline Full-time student & 353 & $30(8.5)$ & & 282 & $24(7.8)$ & \\
\hline Household income & & & $<0.001$ & & & $<0.001$ \\
\hline Less than $1 Q$ & 2879 & $1267(44.0)$ & & 1135 & $444(28.1)$ & \\
\hline $1 Q-2 Q$ & 2882 & 774 (26.9) & & 1615 & 409 (20.2) & \\
\hline $2 Q-3 Q$ & 2879 & $402(14.0)$ & & 2028 & 355 (14.9) & \\
\hline $3 Q+$ & 2886 & $231(8.0)$ & & 2298 & $279(10.8)$ & \\
\hline
\end{tabular}

(OR 1.42, 95\% CI 1.27 to 1.59 ), parental divorce (OR $2.52,95 \%$ CI 1.75 to 3.61$)$, suspension of school education due to financial strain (OR $1.87,95 \%$ CI 1.66 to 2.09) and being raised in a relative's house due to financial strain (OR 2.01, 95\% CI 1.59 to 2.53). The observed associations were attenuated but remained significant when we additionally adjusted for adulthood SES for each of the four CAs. The ORs for having adulthood depressive symptoms for respondents who had one, two, three and four CAs were 1.59 (95\% CI 1.43 to 1.77 ), 2.52 (95\% CI 1.81 to 2.57$), 2.81$ (95\% CI 1.98 to 4.00$)$ and 4.52 (95\% CI 1.53 to 16.10 ), respectively (table 3$)$.

The incidence of adulthood depressive symptoms was associated with childhood experience of parental divorce (OR 1.65, 95\% CI 1.00 to 2.71) and suspension of school education due to financial strain (OR 1.55, 95\% CI 1.32 to 1.82 ). When adulthood SES was adjusted for, in addition to other confounders, the relationship of adulthood depressive symptoms with childhood experience of suspension of school education due to financial strain was attenuated but remained significant (OR 1.38, $95 \%$ CI 1.17 to 1.63 ), whereas the relationship with childhood experience parental divorce was attenuated and became non-significant (OR 1.51, 95\% CI 0.91 to 2.50). The ORs for incidence of adulthood depressive symptoms for respondents who had one, two and three CAs were 1.15 (95\% CI 1.00 to 1.33 ), 1.69 (95\% CI 1.33 to 2.15 ) and 1.64 (95\% CI 0.96 to 2.79 ), respectively (table 4). Because none of the respondents with four CAs developed depressive symptoms, we could not estimate the associated OR among them.

In the age-stratified analyses, prevalence of depressive symptoms was strongly associated with all CAs across all three adulthoods, except for parental divorce and late adulthood depressive symptoms (table 5). In the late adulthood, the prevalence of adulthood depressive symptoms was associated with childhood experience of parental death (OR 1.40, 95\% CI 1.20 to 1.64), suspension of school education due to financial strain (OR $1.87,95 \%$ CI 1.61 to 2.17 ) and being raised in a relative's house due to financial strain (OR 1.58, 95\% CI 1.15 to 2.17$)$. In addition, suspension of school education due to financial strain was associated with incidence of depressive symptoms in late adulthood (OR 1.53, 
Table 2 Distribution of childhood socioeconomic status (SES) and prevalence and incidence of adulthood depressive symptoms in South Korea (2006-2007)

\begin{tabular}{|c|c|c|c|c|c|c|}
\hline \multirow[b]{3}{*}{ Childhood SES } & \multicolumn{3}{|c|}{ Prevalence analysis } & \multicolumn{3}{|c|}{ Incidence analysis } \\
\hline & \multirow{2}{*}{$\begin{array}{l}\text { Total } \\
\mathbf{N}\end{array}$} & \multicolumn{2}{|c|}{ Depressive symptoms } & \multirow{2}{*}{$\begin{array}{l}\text { Total } \\
\mathbf{N}\end{array}$} & \multicolumn{2}{|c|}{ Depressive symptoms } \\
\hline & & $\mathbf{N}(\%)$ & p Value ${ }^{\star}$ & & $\mathbf{N}(\%)$ & p Value ${ }^{\star}$ \\
\hline Education of father & & & $<0.001$ & & & $<0.001$ \\
\hline No education & 3958 & 1313 (33.2) & & 2603 & $622(23.9)$ & \\
\hline Elementary school graduate & 3903 & $808(20.7)$ & & 2944 & $441(15.0)$ & \\
\hline Junior high school graduate & 1402 & $224(16.0)$ & & 1136 & $166(14.6)$ & \\
\hline High school graduate & 1611 & $236(14.7)$ & & 1329 & $173(13.0)$ & \\
\hline University graduate or more & 652 & 93 (14.3) & & 551 & 85 (15.4) & \\
\hline Education of mother & & & $<0.001$ & & & $<0.001$ \\
\hline No education & 5600 & $1732(30.9)$ & & 3760 & $825(21.9)$ & \\
\hline Elementary school graduate & 3612 & 654 (18.1) & & 2851 & $412(14.5)$ & \\
\hline Junior high school graduate & 1170 & $149(12.7)$ & & 967 & $124(12.8)$ & \\
\hline High school graduate & 979 & $120(12.3)$ & & 841 & $107(12.7)$ & \\
\hline University graduate or more & 165 & $20(12.1)$ & & 144 & 19 (13.2) & \\
\hline Occupation of father & & & $<0.001$ & & & 0.003 \\
\hline Non-manual & 1524 & $250(16.4)$ & & 1232 & $177(14.4)$ & \\
\hline Manual & 9639 & $2320(24.1)$ & & 7096 & $1277(18.0)$ & \\
\hline Others & 363 & 105 (28.9) & & 235 & $33(14.0)$ & \\
\hline Occupation of mother & & & $<0.001$ & & & $<0.001$ \\
\hline Non-manual & 104 & $17(16.4)$ & & 84 & $14(16.7)$ & \\
\hline Manual & 8108 & 2049 (25.3) & & 5875 & 1097 (18.7) & \\
\hline Others & 109 & 34 (31.2) & & 70 & 10 (14.3) & \\
\hline Homemaker & 3205 & $575(17.9)$ & & 2534 & $266(14.4)$ & \\
\hline
\end{tabular}

$95 \%$ CI 1.23 to 1.90 ) as well as early adulthood (OR $2.50,95 \%$ CI 1.31 to 4.78 ) and middle adulthood (OR 1.57, $95 \%$ CI 1.21 to 2.03; table 6).

Finally, we assessed whether the association between CA and adulthood depressive symptoms is affected by gender for each of the four CAs after adjusting for age, sex and childhood SES. The gender interaction term was only significant in the association with childhood experience of parental divorce in the prevalence analysis $(p=0.02)$ and in the association with childhood experience of being raised in a relative's house due to financial strain in the incidence analysis $(p=0.018)$. When we examined the gender-specific association after adjusting for age, sex and childhood SES as a post hoc analysis (results are not shown in the table), the association between childhood experience of parental divorce and

Table 3 Association between childhood adversities and prevalence of adulthood depressive symptoms in South Korea (2006-2007, N=11526)

\begin{tabular}{|c|c|c|c|c|c|c|}
\hline \multirow[b]{2}{*}{ Childhood adversities } & \multicolumn{2}{|c|}{ Distribution } & \multicolumn{2}{|l|}{ Model I } & \multicolumn{2}{|c|}{ Model II } \\
\hline & $\mathbf{N}$ & Per cent & OR & $95 \% \mathrm{Cl}$ & OR & $95 \% \mathrm{Cl}$ \\
\hline Parental death & 2072 & 18.0 & $1.42^{\star \star \star}$ & (1.27 to 1.59$)$ & $1.34^{\star \star *}$ & (1.19 to 1.50$)$ \\
\hline Parental divorce & 152 & 1.3 & $2.52^{\star \star \star}$ & (1.75 to 3.61$)$ & $2.07^{\star \star \star}$ & (1.40 to 3.05$)$ \\
\hline Suspension of school education due to financial strain & 1842 & 16.0 & $1.87^{\star \star \star}$ & (1.66 to 2.09$)$ & $1.59^{\star \star \star}$ & (1.41 to 1.80$)$ \\
\hline $\begin{array}{l}\text { Being raised in a relative's house due to financial } \\
\text { strain }\end{array}$ & 352 & 3.1 & $2.01^{\star \star \star}$ & (1.59 to 2.53$)$ & $1.64^{\star \star \star}$ & (1.28 to 2.04$)$ \\
\hline \multicolumn{7}{|l|}{ Number of childhood adversities } \\
\hline 0 & 8102 & 70.3 & 1 & Referent & 1 & Referent \\
\hline 1 & 2594 & 22.5 & $1.59^{\star * *}$ & (1.43 to 1.77$)$ & $1.44^{* * *}$ & (1.29 to 1.61$)$ \\
\hline 2 & 678 & 0.9 & $2.52^{\star \star \star}$ & (1.81 to 2.57$)$ & $1.83^{* * *}$ & (1.52 to 2.19$)$ \\
\hline 3 & 140 & 1.2 & $2.81^{\star \star \star}$ & (1.98 to 4.00$)$ & $2.05^{\star \star \star}$ & (1.41 to 2.97$)$ \\
\hline 4 & 12 & 0.1 & $4.52^{\star \star}$ & (1.53 to 16.10$)$ & $4.50^{*}$ & (1.34 to 15.20$)$ \\
\hline \multicolumn{7}{|c|}{$\begin{array}{l}{ }^{*} p<0.05 . \\
{ }^{* \star} p<0.01 . \\
\text { Mode } p<0.001 \text {. } \\
\text { parent). } \\
\text { Model II: model adjusted for age, sex, four indicators for childhood SES (ie, education and occupation of each parent) and three indicators of } \\
\text { adulthood SES (ie, respondent's education, employment status and household income). }\end{array}$} \\
\hline
\end{tabular}


Table 4 Age-stratified association between childhood adversities and prevalence of adulthood depressive symptoms in South Korea (2006-2007, N=11 526)

\begin{tabular}{|c|c|c|c|c|c|c|}
\hline \multirow[b]{2}{*}{ Childhood adversities } & \multicolumn{2}{|c|}{$\begin{array}{l}\text { Early adulthood } \\
\text { (age 18-39 years) }\end{array}$} & \multicolumn{2}{|c|}{$\begin{array}{l}\text { Middle adulthood } \\
\text { (age 40-59 years) }\end{array}$} & \multicolumn{2}{|c|}{$\begin{array}{l}\text { Late adulthood } \\
\text { (age 60-98 years) }\end{array}$} \\
\hline & $\overline{\text { OR† }}$ & $95 \% \mathrm{Cl} \dagger$ & $\overline{\text { OR† }}$ & $95 \% \mathrm{Cl} \dagger$ & $\overline{\text { ORt }}$ & $95 \% \mathrm{Cl} \dagger$ \\
\hline Parental death & $1.46^{\star \star}$ & (1.11 to 1.93$)$ & $1.46^{\star \star \star}$ & (1.21 to 1.78$)$ & $1.40^{\star \star \star}$ & (1.20 to 1.64$)$ \\
\hline Parental divorce & $2.25^{\star \star \star}$ & (1.44 to 3.51$)$ & $3.53^{\star \star}$ & (1.62 to 7.66$)$ & 5.50 & (0.72 to 41.99$)$ \\
\hline $\begin{array}{l}\text { Suspension of school education } \\
\text { due to financial strain }\end{array}$ & $3.08^{\star \star \star}$ & (1.85 to 5.12$)$ & $1.91^{\star \star \star}$ & (1.57 to 2.32$)$ & $1.87^{\star \star \star}$ & (1.61 to 2.17 ) \\
\hline $\begin{array}{l}\text { Being raised in a relative's house } \\
\text { due to financial strain }\end{array}$ & $2.54^{* *}$ & (1.45 to 4.45$)$ & $2.66^{\star * *}$ & (1.82 to 3.88$)$ & $1.58^{\star *}$ & (1.15 to 2.17$)$ \\
\hline \multicolumn{7}{|l|}{ Number of childhood adversities } \\
\hline 0 & 1 & Referent & 1 & Referent & 1 & Referent \\
\hline 1 & $1.36^{\star}$ & (1.05 to 1.77$)$ & $1.6^{\star \star \star}$ & (1.33 to 1.92$)$ & $1.7^{\star \star \star}$ & (1.46 to 1.99$)$ \\
\hline 2 & $2.92^{\star *}$ & (1.55 to 5.51$)$ & $2.74^{\star * \star}$ & (2.01 to 3.75$)$ & $2.01^{\star \star *}$ & (1.61 to 2.51 ) \\
\hline 3 & $11.33^{\star \star}$ & (2.87 to 44.7$)$ & $2.77^{\star \star \star}$ & (1.59 to 4.80 ) & $2.47^{\star \star \star}$ & (1.57 to 3.91 ) \\
\hline 4 & $5.53^{*}$ & (1.45 to 21.06$)$ & 2.72 & (0.27 to 27.34$)$ & - & - \\
\hline \multicolumn{7}{|l|}{$\begin{array}{l}{ }^{*} p<0.05 . \\
{ }^{\star *} p<0.01 .\end{array}$} \\
\hline
\end{tabular}

the prevalence of adulthood depressive symptoms was observed among women (OR 3.76, 95\% CI 2.34 to 6.03), but not among men (OR 1.31, 95\% CI 0.69 to 2.49) and the strong association between childhood experience of being raised in a relative's house due to financial strain and incidence of adulthood depressive symptoms was also observed only among women (OR $1.89,95 \%$ CI 1.21 to 2.94 ), but not among men (OR $0.81,95 \%$ CI 0.44 to 1.48$)$.

\section{DISCUSSION}

Our findings suggest that CA is associated with the higher incidence of adulthood depressive symptoms as well as the higher prevalence. Strong associations were observed between each of the four CAs and prevalence of adulthood depressive symptoms after adjusting for covariates, including childhood SES as well as adulthood SES. Childhood experience of suspension of school education due to financial strain was strongly associated with incidence of adulthood depressive symptoms. We also found a dose-response relationship between the number of CAs and the prevalence of adulthood depressive symptoms, indicating that respondents with a greater number of CAs were more likely to have adulthood depressive symptoms.

The strong association between CAs and adulthood depressive symptoms is consistent with previous findings

Table 5 Association between childhood adversities and incidence of adulthood depressive symptoms in South Korea (2007, $\mathrm{N}=8563)$

\begin{tabular}{|c|c|c|c|c|c|c|}
\hline \multirow[b]{2}{*}{ Childhood adversities } & \multicolumn{2}{|c|}{ Distribution } & \multicolumn{2}{|l|}{ Model I } & \multicolumn{2}{|l|}{ Model II } \\
\hline & $\mathbf{N}$ & Per cent & OR & $95 \% \mathrm{Cl}$ & OR & $95 \% \mathrm{Cl}$ \\
\hline Parental death & 1370 & 16.0 & 1.07 & (0.92 to 1.24$)$ & 1.02 & (0.88 to 1.19$)$ \\
\hline Parental divorce & 106 & 1.3 & $1.65^{\star}$ & (1.00 to 2.71$)$ & 1.51 & (0.91 to 2.50$)$ \\
\hline Suspension of school education due to financial strain & 1068 & 12.5 & $1.55^{\star \star \star}$ & (1.32 to 1.82$)$ & $1.38^{\star * *}$ & (1.17 to 1.63$)$ \\
\hline $\begin{array}{l}\text { Being raised in a relative's house due to financial strain } \\
\text { Number of childhood adversities }\end{array}$ & 189 & 2.2 & 1.35 & (0.96 to 1.89$)$ & 1.20 & (0.85 to 1.69$)$ \\
\hline 0 & 6378 & 74.5 & 1 & Referent & 1 & Referent \\
\hline 1 & 1716 & 20.0 & 1.1 & (1.00 to 1.33$)$ & 1.07 & (0.93 to 1.24$)$ \\
\hline 2 & 395 & 4.6 & $1.69^{\star \star \star}$ & (1.33 to 2.15$)$ & $1.48^{\star *}$ & (1.16 to 1.88$)$ \\
\hline 3 & 69 & 0.8 & 1.64 & (0.96 to 2.79$)$ & 1.44 & (0.83 to 2.51$)$ \\
\hline 4 & 5 & 0.1 & - & - & - & - \\
\hline \multicolumn{7}{|c|}{$\begin{array}{l}{ }^{*} p<0.05 . \\
{ }^{* \star} p<0.01 . \\
{ }^{* \star \star} p<0.001 . \\
\text { Model I: model adjusted for age, sex and four indicators for childhood socioeconomic status (SES, ie, education and occupation of each } \\
\text { parent). } \\
\text { Model II: model adjusted for age, sex, four indicators for childhood SES (ie, education and occupation of each parent) and three indicators of } \\
\text { adulthood SES (ie, respondent's education, employment status and household income). }\end{array}$} \\
\hline
\end{tabular}


Table 6 Age-stratified association between childhood adversities and incidence of adulthood depressive symptoms in South Korea $(2007, \mathrm{~N}=8563)$

\begin{tabular}{|c|c|c|c|c|c|c|}
\hline \multirow[b]{2}{*}{ Childhood adversities } & \multicolumn{2}{|c|}{$\begin{array}{l}\text { Early adulthood } \\
\text { (age 18-39 years) }\end{array}$} & \multicolumn{2}{|c|}{$\begin{array}{l}\text { Middle adulthood } \\
\text { (age } 40-59 \text { years) }\end{array}$} & \multicolumn{2}{|c|}{$\begin{array}{l}\text { Late adulthood } \\
\text { (age 60-98 years) }\end{array}$} \\
\hline & $\overline{\text { OR† }}$ & $95 \% \mathrm{Cl} \dagger$ & $\overline{\text { OR† }}$ & $95 \% \mathrm{Cl} \dagger$ & $\overline{\text { OR† }}$ & $95 \% \mathrm{Cl} \dagger$ \\
\hline Parental death & 0.77 & (0.54 to 1.12$)$ & 1.18 & (0.91 to 1.54$)$ & 1.13 & (0.91 to 1.42$)$ \\
\hline Parental divorce & $1.89^{\star}$ & (1.13 to 3.14$)$ & 0.52 & (0.07 to 4.15$)$ & - & - \\
\hline $\begin{array}{l}\text { Suspension of school education } \\
\text { due to financial strain }\end{array}$ & $2.50^{\star \star}$ & (1.31 to 4.78$)$ & $1.57^{\star *}$ & (1.21 to 2.03$)$ & $1.53^{\star \star \star}$ & (1.23 to 1.90$)$ \\
\hline $\begin{array}{l}\text { Being raised in a relative's house } \\
\text { due to financial strain }\end{array}$ & 1.39 & (0.68 to 2.86$)$ & 1.39 & (0.77 to 2.51$)$ & 1.31 & (0.79 to 2.16$)$ \\
\hline \multicolumn{7}{|l|}{ Number of childhood adversities } \\
\hline 0 & 1 & Referent & 1 & Referent & 1 & Referent \\
\hline 1 & 0.99 & (0.73 to 1.35$)$ & 1.23 & (0.97 to 1.56$)$ & 1.20 & (0.96 to 1.50$)$ \\
\hline 2 & 1.76 & (0.77 to 4.04$)$ & $1.82^{\star \star}$ & (1.18 to 2.81$)$ & $1.68^{\star \star}$ & (1.23 to 2.29 ) \\
\hline 3 & $5.63^{\star}$ & (1.09 to 29.08 ) & 1.69 & (0.73 to 3.92$)$ & 1.28 & (0.62 to 2.65 ) \\
\hline 4 & - & - & - & - & - & - \\
\hline \multicolumn{7}{|l|}{ *** $p<0.001$} \\
\hline
\end{tabular}

that CAs such as parental death or divorce may be associated with a higher risk of adulthood depressive symptoms. ${ }^{3} 5{ }^{5} 3031$ Korkeila et at reported a dose-response relationship between the number of CAs and depressive symptoms and antidepressant purchase using the Finnish survey data. Similarly, Chapman et $a l^{16}$ reported an association between parental separation or divorce during childhood and lifetime prevalence of depressive disorder, and found that the number of CAs had a dose-response relationship with both lifetime and recent depressive disorders.

In the age-stratified analysis, we found the significant relationships between CAs and the prevalence of adult depressive symptoms maintained in the middle and late adulthood, at least 22 and 42 years after occurrence of the childhood adversities, respectively. CAs had stronger associations with early adulthood prevalence of depressive symptoms than middle or late adulthood, similar to Kessler et $a l \mathrm{~s}^{11}$ study. However, it should be noted that parental divorce, unlike other childhood adversities, showed increase in the magnitude of association with increased age. Although this should not be interpreted as trajectory as it may be due to cohort effect, it suggests that parental divorce may have a unique effect on psychological functioning.

Childhood experience of parental divorce was strongly related to higher prevalence of adulthood depressive symptoms among women, but not among men. This is consistent with a previous finding reporting the significant association between parental divorce and adult depressive symptoms among women, but not among men. ${ }^{15}$ Other studies of the childhood aetiology of suicide also support this finding. Several reports indicate that parental divorce during childhood is associated with lifetime suicide attempt ${ }^{33}$ or suicidal ideation in the past
12 months $^{34}$ only among women. Our findings is also partially supported by the reporting of previous study that women may be more sensitive to CA compared with men. ${ }^{13}$ However, prevalence of parental divorce was lowest among the four CAs $(1.4 \%$ for men and $1.3 \%$ for women), so the estimation of its impact on adulthood depressive symptoms could be relatively unstable. More research with larger sample size is needed to understand whether there is gender difference in the association between childhood parental divorce and mental health outcome and why the difference occurs.

In this study, we assessed two specific childhood experiences related to financial strain as CAs (ie, suspension of school education due to financial strain and being raised in a relative's house due to financial strain) and found their significant associations with adulthood depressive symptoms. These findings are consistent with the previous findings, which reported the association between childhood experience of financial difficulties and adulthood mental health. ${ }^{65}$ Particularly, childhood experience of suspension of school education due to financial strain was significantly associated with both the prevalence and incidence of adulthood depressive symptoms across all three adulthoods, even after being adjusted for childhood and adulthood SES. These findings are supported by the previous studies which reported that educational attainment has significant impact on risk of late-life depression. ${ }^{36}$ This is particularly plausible considering that education level plays a critical role in shaping people's life opportunities in South Korea as we can see that education attainment is the strong determinant of mortality ${ }^{37}$ and is also the most commonly cited reason that people experience discrimination for men and the second common reason for women, following after their sex. ${ }^{38}$ 
As a post hoc analysis, we conducted data analysis for prevalence and incidence of adulthood depressive symptoms by including four different CAs simultaneously because different CAs were correlated to each other. After adjusting for potential confounders (ie, age, sex and four indicators for childhood SES), prevalence of adulthood depressive symptoms was associated with childhood experience of parental death (OR 1.23, 95\% CI 1.09 to 1.39 ), parental divorce (OR 1.92, $95 \%$ CI 1.30 to 2.84), suspension of school education due to financial strain (OR 1.50, 95\% CI 1.33 to 1.70 ) and being raised in a relative's house due to financial strain (OR 1.26, 95\% CI 0.96 to 1.63$)$. In the incidence analysis, only the association between suspension of school education due to financial strain and adulthood depressive symptoms (OR $1.38,95 \%$ CI 1.16 to 1.63 ) was significant whereas the other three associations turned out to be nonsignificant. However, these results should be interpreted cautiously because some CAs could be located in the pathway linking other CAs to adulthood depressive symptoms. For example, the people who experienced parental divorce or parental death during their childhood are more likely to be raised in a relative's house due to financial burden. In this case, adjustment of being raised in a relative's house could lead to over-adjustment because the variable could be an intermediate variable between childhood parental divorce or death and adulthood depressive symptoms.

Several explanations can support a pathway linking CA to adulthood depressive symptoms. People who experienced hardship in childhood may develop a learned helplessness or difficulty in establishing attachments, making them more vulnerable to stressful life events, which could lead to depressive symptoms. ${ }^{34}{ }^{24}$ Ross and Mirowsky ${ }^{14}$ reported that adults with childhood experience of parental divorce exhibit problems in interpersonal relationships, such as finding themselves in unhappy relationships or mistrusting people in general and reflecting difficulties in establishing secure attachment. Finally, biologically speaking, previous studies suggest that CAs could sensitise the neuroendocrine stress responses of the hypothalamic-pituitary-adrenal axis over the course of lifetime, leading to depressive symptoms. $^{39}$

This study has several limitations. First, although we assessed four different CAs, other CAs such as physical abuse or emotional abuse that are known to be associated with adulthood depressive symptoms, ${ }^{16-18}$ were not measured in this study. Future studies in South Korea need to investigate the association between CA and adulthood depressive symptoms with more comprehensive measures of CA. Second, adulthood depressive symptoms may influence CA reporting. But, the incidence analysis, which analysed the subpopulation that were not-depressed when they reported their CAs at first wave of KOWEP, still revealed a significant association between CAs and adulthood depressive symptoms. Furthermore, CAs such as parent death or parental divorce are less prone to recall bias because it designates a definite life event, whereas a report on childhood abuse is more likely to be over-reported among depressed. Therefore, we do not think that the observed strong association could be fully explained by potential recall bias.

The present study has several strengths. First, because of the longitudinal study design, we could examine the association between CA and incidence of adulthood depressive symptoms at second wave of KOWEPS (2007) after excluding the people with depressive symptoms at first wave of KOWEPS (2006). Second, we found a gender difference in the association between childhood experience of parental divorce and being raised in a relative's house due to financial strain during childhood and adulthood depressive symptoms. Third, this study found a strong association between $\mathrm{CA}$ and adulthood depressive symptoms after adjusting for adulthood SES as well as potential confounders including childhood SES. Finally, this is, to our knowledge, the first study identifying the childhood aetiology of adulthood depressive symptoms in South Korea.

\section{CONCLUSIONS}

This study suggests that CA may increase the likelihood of having adulthood depressive symptoms after adjusting for adulthood SES as well as potential confounders including childhood SES, and that the associations between childhood experience of parental divorce and adulthood depressive symptoms may be different by gender. These findings imply that early intervention during childhood to reduce CA may be an important strategy to improve mental health throughout the life course.

\section{Author affiliations \\ ${ }^{1}$ Healthcare Management, Korea University, Seoul, Korea \\ ${ }^{2}$ Department of Social and Behavioral Sciences, Harvard School of Public Health, Boston, Massachusetts, USA \\ ${ }^{3}$ Department of Environmental and Occupational Health, The George \\ Washington University School of Public Health and Health Services, \\ Washington, District of Columbia, USA \\ ${ }^{4}$ Master of Public Health Program, Harvard School of Public Health, Boston, Massachusetts, USA \\ ${ }^{5}$ Master of Public Health Program, Columbia University Mailman School of Public Health, New York, New York, USA \\ ${ }^{6}$ Department of Psychiatry, Yonsei University College of Medicine, Seoul, Korea \\ ${ }^{7}$ Department of Anthropology, Stanford University, Stanford, California, USA ${ }^{8}$ Department of Epidemiology, Graduate School of Public Health, Seoul National University, Seoul, Korea}

Contributors SSK conceptualised the study and analysed the data. SSK, HJ, YSP and DWL wrote the first draft. HYC reviewed the draft and provided critical comments on it. All authors participated in revising the final version of the manuscript.

Funding This research received no specific grant from any funding agency in the public, commercial or not-for-profit sectors.

Competing interests None.

Patient consent Obtained. 
Ethics approval This research received Institutional Review Board (IRB) exemption from the Office of Human Research Administration at the Harvard School of Public Health.

Provenance and peer review Not commissioned; externally peer reviewed.

Data sharing statement We analysed the publicly available dataset, Korean Welfare Panel Study. The dataset used in this study can be downloaded from the website (http://www.koweps.re.kr).

Open Access This is an Open Access article distributed in accordance with the Creative Commons Attribution Non Commercial (CC BY-NC 3.0) license, which permits others to distribute, remix, adapt, build upon this work noncommercially, and license their derivative works on different terms, provided the original work is properly cited and the use is non-commercial. See: http:// creativecommons.org/licenses/by-nc/3.0/

\section{REFERENCES}

1. Lopez AD, Mathers CD, Ezzati M, et al. Global and regional burden of disease and risk factors, 2001: systematic analysis of population health data. Lancet 2006;367:1747-57.

2. World Health Organization. The global burden of disease: 2004 update. Geneva: World Health Organization, 2008.

3. Kendler KS, Kuhn JW, Prescott CA. Childhood sexual abuse stressful life events and risk for major depression in women. Psychol Med 2004;34:1475-82.

4. Pesonen A-K, Räikkönen K, Heinonen K, et al. Depressive symptoms in adults separated from their parents as children: a natural experiment during World War II. Am J Epidemiol 2007:166:1126-33.

5. Kessler RC, Magee WJ. Childhood adversities and adult depression: basic patterns of association in a US national survey. Psychol Med 1993;23:679-90.

6. Korkeila J, Vahtera J, Nabi H, et al. Childhood adversities, adulthood life events and depression. $J$ Affect Disord 2010;127:130-8.

7. Jacobs JR, Bovasso GB. Re-examining the long-term effects of experiencing parental death in childhood on adult psychopathology. J Nerv Ment Dis 2009;197:24-7.

8. Reinherz HZ, Giaconia RM, Hauf AM, et al. Major depression in the transition to adulthood: risks and impairments. J Abnorm Psychol 1999;108:500-10.

9. Stikkelbroek $Y$, Prinzie $P$, De Graaf $R$, et al. Parental death during childhood and psychopathology in adulthood. Psychiatry Res 2012;198:516-20.

10. Perris $C$, Holmgren $S$, Von Knorring $L$, et al. Parental loss by death in the early childhood of depressed patients and of their healthy siblings. Br J Psychiatry 1986;148:165-9.

11. Kessler RC, Davis CG, Kendler KS. Childhood adversity and adult psychiatric disorder in the US National Comorbidity Survey. Psychol Med 1997;27:1101-19.

12. Oakley-Browne MA, Joyce PR, Wells JE, et al. Adverse parenting and other childhood experience as risk factors for depression in women aged 18-44 years. J Affect Disord 1995;34:13-23.

13. Piccinelli M, Wilkinson G. Gender differences in depression. $\mathrm{Br} J$ Psychiatry 2000;177:486-92.

14. Ross CE, Mirowsky J. Parental divorce, life-course disruption, and adult depression. J Marriage Fam 1999;61:1034-45.

15. McLeod JD. Childhood parental loss and adult depression. $J$ Health Social Behav 1991;32:205-20.

16. Chapman DP, Whitfield CL, Felitti VJ, et al. Adverse childhood experiences and the risk of depressive disorders in adulthood. $J$ Affect Disord 2004;82:217-25.

17. Bifulco A, Brown GW, Adler Z. Early sexual abuse and clinical depression in adult life. Br J Psychiatry 1991;159:115-22.
18. Wainwright NWJ, Surtees PG. Childhood adversity, gender and depression over the life-course. J Affect Disord 2002;72:33-44.

19. Cong E, Li Y, Shao C, et al. Childhood sexual abuse and the risk for recurrent major depression in Chinese women. Psychol Med 2012;42:409-17.

20. Takeuchi $\mathrm{H}$, Hiroe $\mathrm{T}$, Kanai $\mathrm{T}$, et al. Childhood parental separation experiences and depressive symptomatology in acute major depression. Psychiatry Clin Neurosci 2003;57:215-19.

21. Cho MJ, Kim KH. Use of the Center for Epidemiologic Studies Depression (CES-D) Scale in Korea. J Nerv Ment Dis 1998; $186: 304-10$

22. Takeshita J, Masaki K, Ahmed I, et al. Are depressive symptoms a risk factor for mortality in elderly Japanese American men?: the Honolulu-Asia Aging Study. Am J Psychiatry 2002;159:1127-32.

23. Harper S, Lynch J, Hsu WL, et al. Life course socioeconomic conditions and adult psychosocial functioning. Int $J$ Epidemiol 2002;31:395-403.

24. Gilman SE, Kawachi I, Fitzmaurice GM, et al. Socioeconomic status in childhood and the lifetime risk of major depression. Int $J$ Epidemiol 2002;31:359-67.

25. International Labour Organisation. International Standard Classification of Occupation. Secondary International Standard Classification of Occupation. 2008. http://www.ilo.org/public/english/ bureau/stat/isco/isco08/index.htm

26. Seo J-H, Kim H, Shin Y-J. Analysis for the impact of adulthood and childhood socioeconomic positions and intergenerational social mobility on adulthood health. $J$ Prev Med Public Health 2010;43:138-50.

27. Kim S-S, Chung Y, Perry MJ, et al. Association between interpersonal trust, reciprocity, and depression in South Korea: a prospective analysis. PLOS ONE 2012;7:e30602.

28. Kim S-S, Subramanian SV, Sorensen G, et al. Association between change in employment status and new-onset depressive symptoms in South Korea-a gender analysis. Scand J Work Environ Health 2012;38:537-45.

29. Rogers WH. Regression standard errors in clustered samples. Stata Tech Bull 1987;13:19-23.

30. Gilman SE, Kawachi I, Fitzmaurice GM, et al. Family disruption in childhood and risk of adult depression. Am J Psychiatry 2003;160:939-46.

31. Comijs HC, Beekman ATF, Smit F, et al. Childhood adversity, recent life events and depression in late life. $J$ Affect Disord 2007;103:243-6.

32. Rodgers B. Pathways between parental divorce and adult depression. J Child Psychol Psychiatry 1994;35:1289-308.

33. Lizardi D, Thompson RG, Keyes K, et al. Parental divorce, parental depression, and gender differences in adult offspring suicide attempt. J Nerv Ment Dis 2009;197:899-904.

34. De Goede M, Spruijt E. Effects of parental divorce and youth unemployment on adolescent health. Patient Educ Couns 1996;29:269-76.

35. Korkeila K, Kivelä S-L, Suominen S, et al. Childhood adversities, parent-child relationships and dispositional optimism in adulthood. Soc Psychiatry Psychiatr Epidemiol 2004;39:286-92.

36. Ladin K. Risk of late-life depression across 10 European Union countries: deconstructing the education effect. J Aging Health 2008;20:653-70.

37. Khang YH, Lynch JW, Kaplan GA. Health inequalities in Korea: ageand sex-specific educational differences in the 10 leading causes of death. Int J Epidemiol 2004;33:299-308.

38. Kim S-S, Williams DR. Perceived discrimination and self-rated health in South Korea: a nationally representative survey. PLOS ONE 2012:7:e30501.

39. Bradley RG, Binder EB, Epstein MP, et al. Influence of child abuse on adult depression: Moderation by the corticotropin-releasing hormone receptor gene. Arch Gen Psychiatry 2008:65:190-200. 